\title{
A 16-Year-Old Female with Peutz-Jeghers Syndrome
}

\author{
Mufti Munsurar Rahman ${ }^{1}$, Mamunur Rashid ${ }^{2}$, Rukhsana Parvin ${ }^{3}$, Arun Joyati Tarafder ${ }^{4}$ \\ Received: May 13, 2014 Accepted: June 14, 2014
}

\begin{abstract}
Peutz-Jeghers syndrome is a rare autosomal dominant disorder of hamartomatous polyposis of the gastrointestinal tract, with pigmentation around lips and macules on the buccal mucosa that typically manifests itself as recurrent colicky abdominal pain and intestinal obstruction due to intussusception. Here we report a case of a 16-year-old girl who presented with abdominal pain, vomiting and previous history of laparotomy for intussusception. Multiple well demarcated black pigmented macules on lips, perioral region, buccal mucosa, digits, palms and soles were noted. She was diagnosed as a case of Peutz-Jeghers syndrome and managed conservatively.
\end{abstract}

Key words: Peutz-Jeghers syndrome; Intussusception; Polyps; Circumoral pigmentation

J Enam Med Col 2014; 4(3): 184-187

\section{Introduction}

Peutz-Jeghers syndrome (PJS), also known as hereditary intestinal polyposis syndrome, is an autosomal dominant genetic disease characterized by the development of benign hamartomatous polyps in the gastrointestinal tract, presence of hyperpigmented macules on the lips and oral mucosa (melanosis) and susceptibility to multiple cancers. ${ }^{1}$ It has an incidence of approximately 1 in 120000 births. $^{2}$

A clinical diagnosis of PJS may be made when any one of the following conditions is present in a single individual: two or more histologically confirmed PeutzJeghers (PJ) polyps; any number of PJ polyps detected in an individual who has a family history of PJS in a close relative; characteristic mucocutaneous pigmentation in an individual who has a family history of PJS in a close relative or any number of PJ polyps in an individual who also has characteristic mucocutaneous pigmentation. ${ }^{3}$

The disease affects males and females equally. In addition to polyposis, the risk of gastrointestinal and extra-gastrointestinal malignancies is significantly increased in PJS patients. ${ }^{4}$ The risk of any other malignancy (especially cancer of the reproductive organs, breast, pancreas and lung) is nine times greater than in the general population. ${ }^{5} \mathrm{~A}$ few years ago, two independent groups of investigators defined the mutated gene responsible for PJS.6,7 The gene was localized to chromosome 19p34-p36 and is known as STK 11, a serine-threonine kinase involved in growth control regulation. ${ }^{8}$ On the other hand, not all patients with PJS have a mutation in this gene. ${ }^{9}$ Here we report a case of a 16-year-old girl who presented with abdominal pain, vomiting and previous history of laparotomy for intussusceptions and subsequently was diagnosed as a case of PJS.

\section{Case report}

A 16-year-old girl presented in the Medicine OPD in Enam Medical College Hospital with the complaints of abdominal pain and vomiting. Multiple black pigmented macules on lips, perioral region, buccal mucosa, digits, palms and soles were noted (Fig 1,2). Few months back she was admitted in the department of

1. Professor, Department of Medicine, Enam Medical College \& Hospital, Savar, Dhaka

2. Registrar, Department of Medicine, Enam Medical College \& Hospital, Savar, Dhaka

3. Associate Professor, Department of Medicine, Enam Medical College \& Hospital, Savar, Dhaka

4. Assistant Professor, Department of Hepatology, Mymensingh Medical College \& Hospital, Mymensingh

Correspondence Mamunur Rashid, Email: mamunurdr@yahoo.com 
Surgery with same complaints and was diagnosed as a case of intussusception and exploratory laparotomy was done. Intraoperatively, jejuno-jejunal and ileo-colic intussusceptions were found and nobel multiple sites plication was done. No polyp was felt manually and no enterotomy or enteroscopy was done at that time.

The patient did not have positive family history of PJS or any other polyposis syndrome. Barium followthrough radiography was done and it showed multiple filling defects through entire small intestine (Fig 3). Endoscopy of upper gastrointestinal (GI) tract revealed several polyps of different sizes in stomach and duodenum (Fig 4, 5). PJS was diagnosed on the basis of presence of polyps and characteristic pigmentation. She was managed conservatively and counseled and advised to come for regular follow-up.

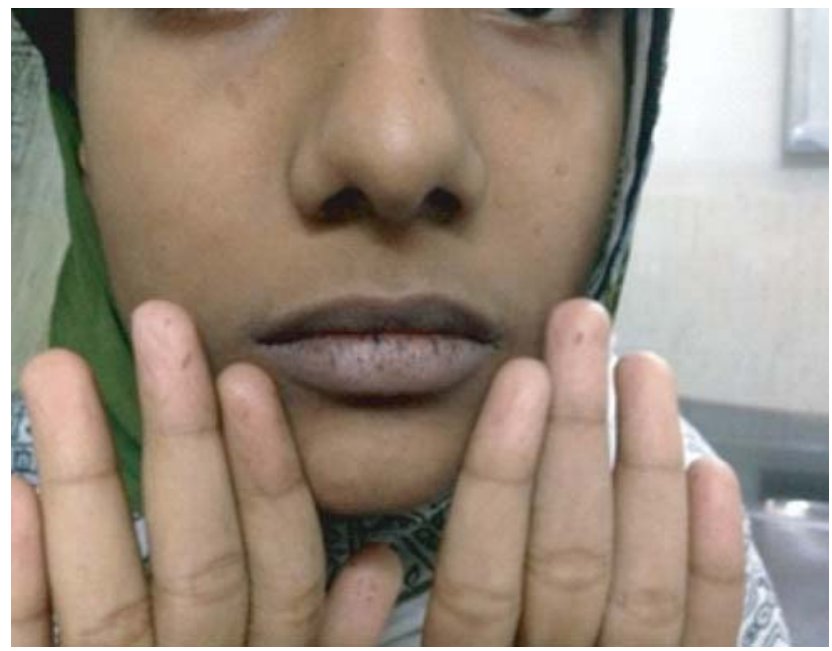

Fig 1. Hyperpigmentation in lips and finger pulp

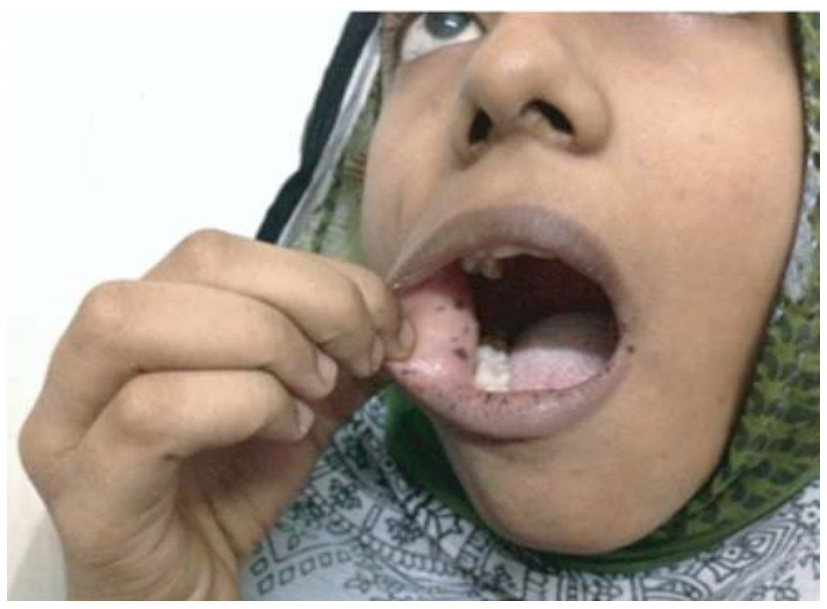

Fig 2. Hyperpigmentation in buccal mucosa

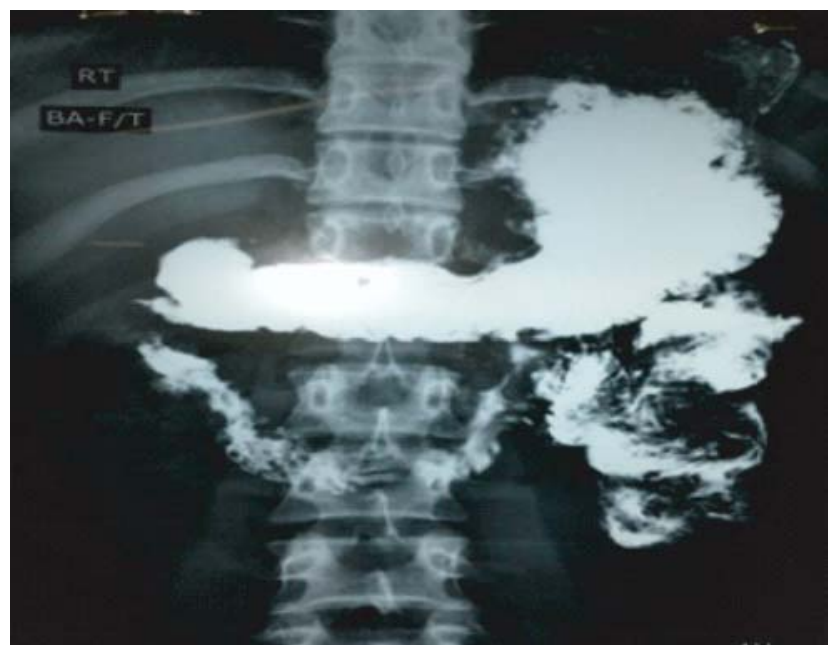

Fig 3. Barium follow-through X-ray showing multiple filling defects in small intestine

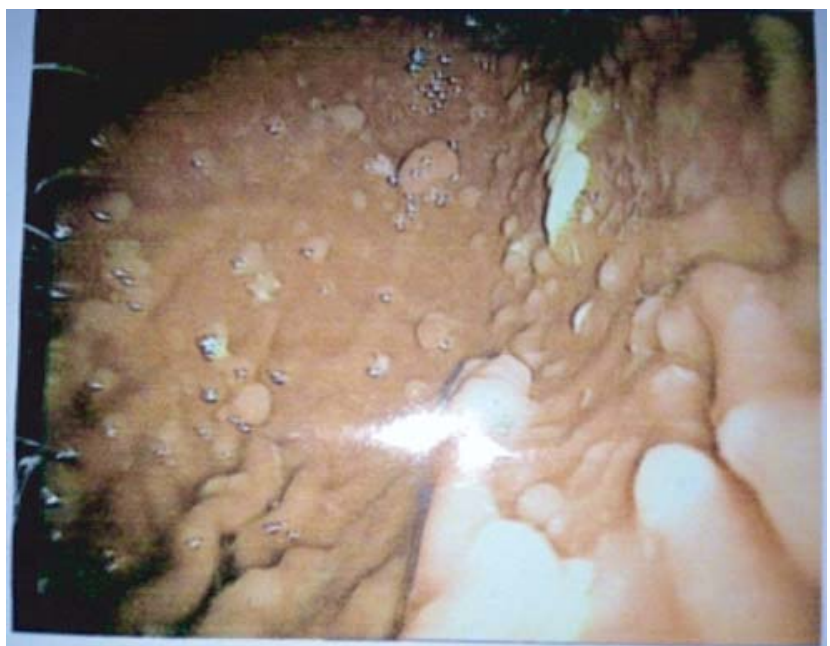

Fig 4. Endoscopy of upper GIT showing multiple polyps in stomach

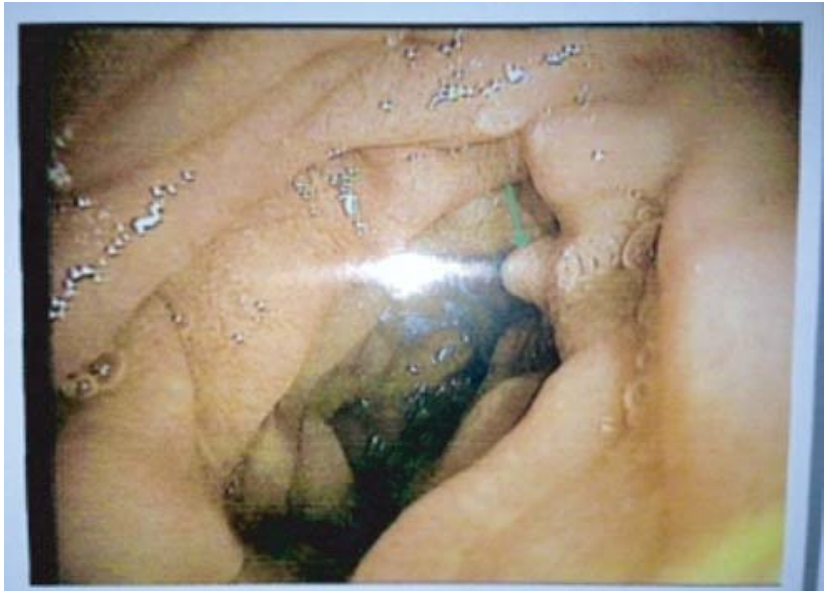

Fig 5. Endoscopy of upper GIT showing multiple polyps in duodenum 


\section{Discussion}

PJS comprises multiple polyps of the stomach and bowel leading to transient intussusception and a brownish pigmentation around the mouth and lips. The melanin spots of PJS are present in more than $90 \%$ of patients and occur most commonly on the lips and buccal mucosa, but are found also on circumoral and facial skin, on the palms and soles and on the digits. ${ }^{10}$ The melanotic macules on the skin may not develop until after the intestinal polyps and may fade with age. ${ }^{11}$ In this case, the patient had melanin spots in the circumoral region, digits, palms and soles.

Polyposis occurs most often in the intestinal tract, but can be found in nasal, bladder or gallbladder mucosa and in the pelvis or lungs. ${ }^{12}$ In the intestinal tract, early polyposis leads to clinical signs. Onethird of the time, first manifestations occur during the first decade of life; in one-half cases these occur before 20 years and sometimes it occurs in the neonatal period. ${ }^{13}$ This hamartomatous polyposis is located in the small bowel in $90 \%$ of patients, most often in jejunum, followed by ileum and duodenum. ${ }^{14}$ It is also found in the stomach (24\%) and colon (9\%). Most polyps are pedunculated, except on the gastric wall where they are sessile. They are mainly diagnosed by clinical manifestations secondary to complications, such as acute intestinal intussusception (43\%), iron deficiency anemia (14\%) linked with polyp ulceration, chronic abdominal pain $(23 \%)$, anal prolapse of rectal polyp (7\%), or transforming into gastrointestinal tract adenocarcinoma $(2-3 \%) .{ }^{13}$

Follow-up of this polyposis disease raises the problem of its main localization in the small bowel, which is difficult to investigate. There are various endoscopic tools, but videocapsule endoscopy seems to be the easiest to use and of best quality for standard polyposis screening. Among endoscopic tools, double-balloon enteroscopy helps in proper diagnosis and location of polyps and permits the surgeon to resect or biopsy these polyps. ${ }^{15}$ Periodic endoscopic screenings are advocated every 2 years. ${ }^{16}$

Intussusception occurs when one loop of bowel telescopes into an adjacent segment. This has been observed in $47-69 \%$ of adult patients with PJS and most of them were due to polyps located in the small intestine. ${ }^{17}$ The majority of intussusceptions reported in the literature are in ileal or jejunal regions. ${ }^{18,19}$ Colo-colonic intussusception is reported in only a few cases. ${ }^{20}$ In this case, the patient developed jejuno-jejunal and ileo-colic intussusceptions.

Screening should not be restricted to the gastrointestinal tract. Because of the increased risk of malignancy, it is essential to set surveillance guidelines based on a high cancer risk adjusted for the patient's age and the organ involved. All reports recommend establishing a familial register and screening all possible patients with genetic analysis.

In conclusion, it is important to be vigilant and observant about the patients who have circumoral pigmentation and to go into the depth of history and physical findings. Patients with PJS should be regularly and closely monitored, so that it can reduce the risk of cancer and also reduce the number of laparotomies.

\section{Acknowledgement}

We thank Professor Md. Khalilur Rahman, Department of Surgery, Enam Medical College \& Hospital, Savar, Dhaka and Dr. Irin Perveen, Associate professor, Department of Gastroenterology, Enam Medical College \& Hospital, Savar, Dhaka for their cooperation.

\section{References}

1. Buck JL, Harned RK, Lichtenstein JE, Sobin LH. Peutz-Jeghers syndrome. Radiographics 1992; 12: 365-368.

2. McGarrity TJ, Kulin HE, Zaino RJ. Peutz-Jeghers syndrome. Am J Gastroenterol 2000; 95: 596-604.

3. Beggs AD, Latchford AR, Vasen HF, Moslein G, Alonso A, Aretz $\mathrm{S}$ et al. Peutz-Jeghers syndrome: a systematic review and recommendations for management. Gut 2010; 8: 975-986.

4. Boardman LA, Thibodeau SN, Schaid DJ, Lindor NM, McDonnell SK, Burgart LJ et al. Increased risk for cancer in patients with the Peutz-Jeghers syndrome. Ann Intern Med 1998; 128(11): 896-899.

5. Spigelman AD, Murday V, Phillips RK. Cancer and the PeutzJeghers syndrome. Gut 1989; 30(11): 1588-1590.

6. Jenne DE, Reimann H, Nezu J, Friedel W, Loff S, Jeschke R et al. Peutz-Jeghers syndrome is caused by mutations in a novel serine threonine. Nat Genet 1998; 18(1): 38-43.

7. Hemminki A, Markie D, Tomlinson I, Avizienyte E, Roth S, Loukola A et al. A serine/threonine kinase gene defective in Peutz-Jeghers syndrome. Nature 1998; 391(6663): 184-187. 
8. Hemminki A, Tomlinson I, Markie D, Jarvinen H, Sistonen $\mathrm{P}$, Bjorkqvist AM et al. Localization of a susceptibility locus for Peutz-Jeghers syndrome to $19 p$ using comparative genomic hybridization and targeted linkage analysis. Nat Genet 1997; 15(1): 87-90.

9. Boardman LA, Couch FJ, Burgart LJ, Schwartz D, Berry R, McDonnell SK et al. Genetic heterogeneity in Peutz-Jeghers syndrome. Hum Mutant 2000; 16: 23-30.

10. Burdick D. Prior JT. Peutz-Jeghers syndrome: a clinicopathologic study of a large family with a 27 years follow-up. Cancer 1982; 50: 2139-2146.

11. Bartholomew LG, Moore CE, Dahlin DC, Waugh JM. Intestinal polyposis associated with mucocutaneous pigmentation. Surg Gyne Col Obstet 1962: 115: 1-11.

12. Schreibman IR, Baker M, Amos C, McGarrity TJ. The hamartomatous polyposis syndromes: a clinical and molecular review. Am J Gastroenterol 2005; 2: 476-490.

13. Boseto F, Shi E, Mitchell J, Preddy J, Adams S. Gastroduodenal intussusception due to Peutz-Jeghers syndrome in infancy. Pediatr Surg Int 2002; 18(2-3): 178-180.

14. McGarrity TJ, Kulin HE, Zaino RJ. Peutz-Jeghers syndrome. Am J Gastroenterol 2000; 3: 596-604.
15. Ohmiya N, Taguchi A, Shirai K, Mabuchi N, Arakawa D, Kanazawa $\mathrm{H}$ et al. Endoscopic resection of Peutz-Jeghers polyps throughout the small intestine at double-balloon enteroscopy without laparotomy. Gastrointest Endosc 2005; 1: 140-147.

16. Hinds R, Philp C, Hyer W, Fell JM. Complications of childhood Peutz-Jeghers syndrome: implications for pediatric screening. J Pediatr Gastroenterol Nutr 2004; 39(2): 219-220.

17. Wang H, Luo T, Liu WQ, Huang Y, Wu XT, Wang XJ. Clinical presentations and surgical approach of acute intussusception caused by Peutz-Jeghers syndrome in adults. J Gastrointest Surg 2011; 8: 2218-2225.

18. Chen XD, Yu YY, Yang L, Rui YY, Zhou ZG. Duodenal intussusception due to a giant neuroendocrine carcinoma in a patient with Peutz-Jeghers syndrome: case report and systematic review. Eur J Gastroenterol Hepatol 2012; 8: 722-726.

19. Jason FD, Steven EB, Shawn DP, Giovanni DP, Heppell J. Intussusception in the adult: an unsuspected case of Peutz-Jeghers syndrome with review of the literature. Fam Cancer 2009; 8: 95-101.

20. Jaremko JL, Rawat B. Colo-colonic intussusception caused by a solitary Peutz-Jeghers polyp. Br J Radiol 2005; 8: 1047-1049. 